OBSERVAÇŌES CITOLÓGICAS EM "MÓSCAS DAS FRUTAS" (*). Luiz O. T. Mendes. Com o fim de verificar a possibilidade de identificar especificamente "môscas das frutas" pelo exame citológico de tecido somático de estados imaturos, o autor, em várias ocasiões (1940, 1947 e 1948) fêz alguns estudos. Ainda que bastante incompletos, os resultados foram positivos, pelo que são aqui apresentados.

Três espécies de môscas foram examinadas e identificadas: Lonchaea pendula Bezzi, da família Lonchaeidae, Anastrepha fratereulus (Wied.) e Ceratitis capitata (Wied.), ambas da família Trypetidae.

Pelo exame morfológico não há dificuldade em se separar uma larva de L. pendula Bezzi de larvas de representantes da familia Trypetidae; no entanto, não é fácil a identificação específica de larvas de A. fraterculus (Wied.) e de C. capitata (Wied.), quando juntas. Sua identificação pelo estudo do complemento cromossômico é, portanto, de grande utilidade.

MATERIAL E METODO. Os estudos foram feitos em tecidos somático (gânglios nervosos de larvas e pupas) e germinal (testículos de pupas e adultos e ovários de adultos). Nos casos de material obtido de larvas, antes de seu estudo citológico desconhecia-se a identificação específica do inseto; já para o caso das pupas e adultos, suo identidade sempre foi antes determinada com segurança.

O material foi colorido com aceto-carmim-férrico ou orceina acética, da maneira usual; os desenhos foram feitos com câmara clara.

\title{
LONCHAEA PENDULA BEZZI
}

Foram estudadas larvas coletadas em laranja (Campinas, julho de 1940), marmelo (Campinas, fevereiro de 1948) e laranja Pêra (Limeira, agôsto de 1948); sòmente foram examinadas lâminas preparadas com tecido nervoso, colorido pelo aceto-carmim-férrico.

No tecido somático foram observados seis cromossomos grandes $(2 n=6)$ que, em placas metafásicas, quase sempre acham-se dispostos aos pares (fig. 1 a 4). Em todos os cromossomos o centrômero parece ser mediano (fig. 5 e 6), dividindo-os em dois braços de aproximadamente igual tamanho; em alguns casos parece ser de localização sub-

(*) Recebida para publicoçāo em 20 de setembro de 1958. 
mediana (fig. 9). A localização de centrômetro é fàcilmente visível. Em figura anafásica foi observado que todos os cromossomos movimentam-se para os polos com a forma de $V$, com o vértice voltado para o polo, como seria de se esperar.

Em prófase os cromossomos apresentam-se muito longos, cons-
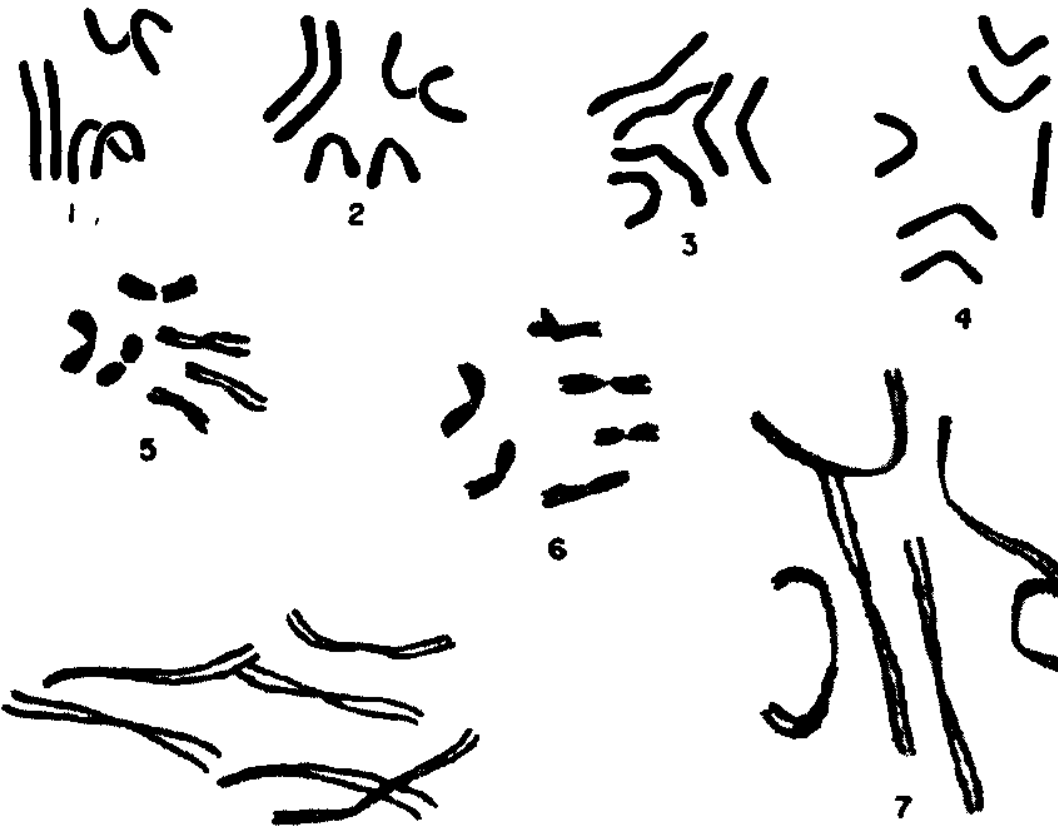

10
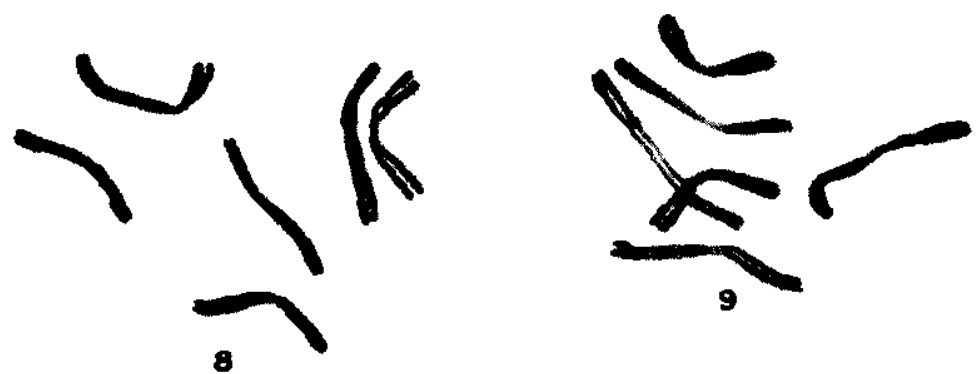

FIGURA 1-10. Lonchaea pendula Bezzi: 1-4 - metáfoses em gânglio nervoso de larva coletada em laranja (Campinas, julho de 1940); 5-6 - pré-metáfases em gânglio nervoso de larva coletado em marmelo (Campinas, fevereiro de 1940); 7-10 - prófases em gânglio nervoso de larva coletada em laranja Pêra (Limeira, agôsto de 1948). 
tituidos de dois cromatídeos dispostos paralelamente, bem visíveis (fig. 7 a 10).

Não foram feitos exames em figuras meióticas, mas pode-se concluir que o número haploide é três $(n=3)$.

\section{ANASTREPHA FRATERCLLTS (WIED.)}

Foram estudados: a) tecido nervoso de larvas obtidas de laranjas (Compinas, setembro de 1947), colorido com aceto-carmim-férrico; b) testículos de pupas e adultos obtidos de nêspera (Limeira, outubro de 1947), coloridos com orceina acética.

Em tecido somático de larvas, machos e fêmeas, encontram-se sempre 12 cromossomos $(2 n=12)$.

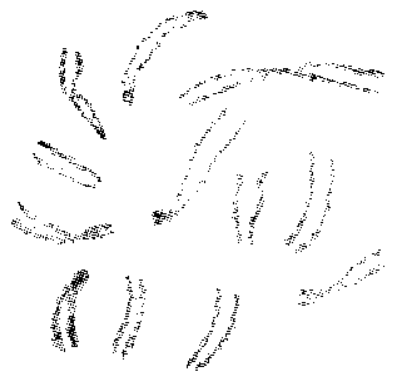

II

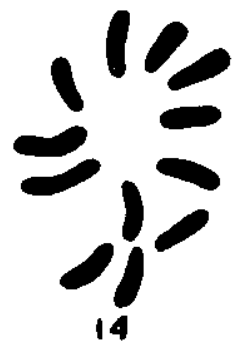

14

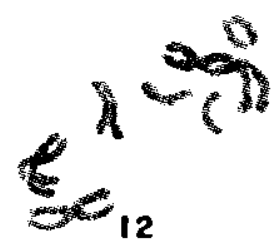

12

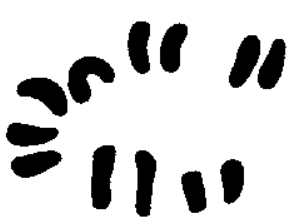

15

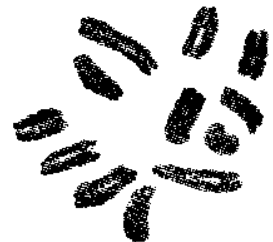

13
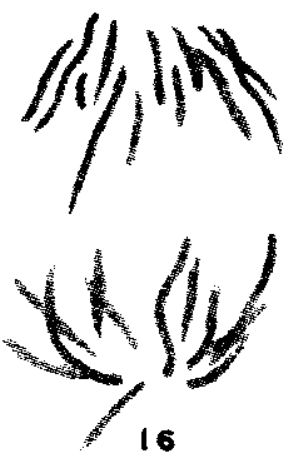

Figura 11-16. \& Anastrepha fraterculus (Wied.): 17 - prófase; 12 - prófose adiantoda; 13 - pré-metáfase; 14-15 - metáfases; 16 - anáfase. Tôdas em gânglios nervosos de larvas coletadas em laranja (Campinas, sctembro de 1947). 
Nas larvas fêmeas, em prófase os cromossomos mostram dois cromatídeos longos, paralelamente dispostos, muitas vêzes bastante afastado um do outro (fig. 11); em figuras em que foi observado visível pareamento somático, foram encontrados pares de cromossomos enrolados em espiral (fig. 12). Em pré-metáfase ainda podem ser observados os dois cromatídeos de cada cromossomo (fig. 13). As placas metafásicas mostram 12 cromossomos em forma de bastonete grosso, com pequenas diferenças em seu tamanho, dispostos aos pares (fig. 14-15). Em anáfase todos os cromossomos apresentam uma extremidade voltada para o polo (fig. 16).

Nas lorvas machas, as figuras profásicas mostram a existência de 12 cromossomos constituidos de dois cromatídeos paralelamente dispostos; um dos cromossomos é de tamanho bem menor que os demais (fig. 17-18). Em prófase mais adiantada é bastante visível o pareamento de cinco pares de cromossomos homólogos, alguns dêles enrolados em espiral (fig. 19-20); os hetero-cromossomos, um longo e outro pequeno, podem ser encontrados próximos entre si (fig. 20) ou afastados (fig. 19). Em metáfase também se nota o pareamento dos cromossomos homólogos (fig. 21, 22, 23, 24, 26), os dois não homólogos muitas vêzes encontrando-se próximos um do outro, o pequeno perto de uma das extremidades do grande (fig. 22, 23, 24). Em muitos casos foi observado o hetero-cromossomo pequeno em posição aproximadamente central, na placa metafásica (fig. 22, 25 e 26). Em anáfase os cromossomos são observados dispostos ao longo dos fusos, com uma extremidade voltada para o polo (fig. 27 e 28).

A existência de seis pares de cromossomos em tecido somático da larva fêmea, e, na larva macha, de cinco pares e dois cromossomos não homólogos( um grande e um pequeno), leva à conclusão ser a fêmea de constituição $10 \mathrm{~A}+\mathrm{XX}$ e o macho $10 \mathrm{~A}+\mathrm{XY}$, sendo $\mathrm{Y}$ o hetero-cromossomo pequeno.

Não foi possível distinguir, nas figuras mitóticas obtidas de larvas fêmeas, quais eram os cromossomos $X$; nas preparações com tecido masculino, no entanto, foi possível reconhecer o cromossomo $X$, além do $Y$, de fácil distinção. Em preparação de testículo de pupa (obtida de nêspera, Limeira, outubro de 1947), em quatro placas metafásicas espermatogoniais, um estudo acurado das figuros permitiu a perfeita identificação dêsses cromossomos (fig. 29 a 32). Em outras preparações de tecido nervoso de larvas, a identificação do cromossomo $X$ nem sempre foi possivelmente certa, mas mesmo assim é êle 

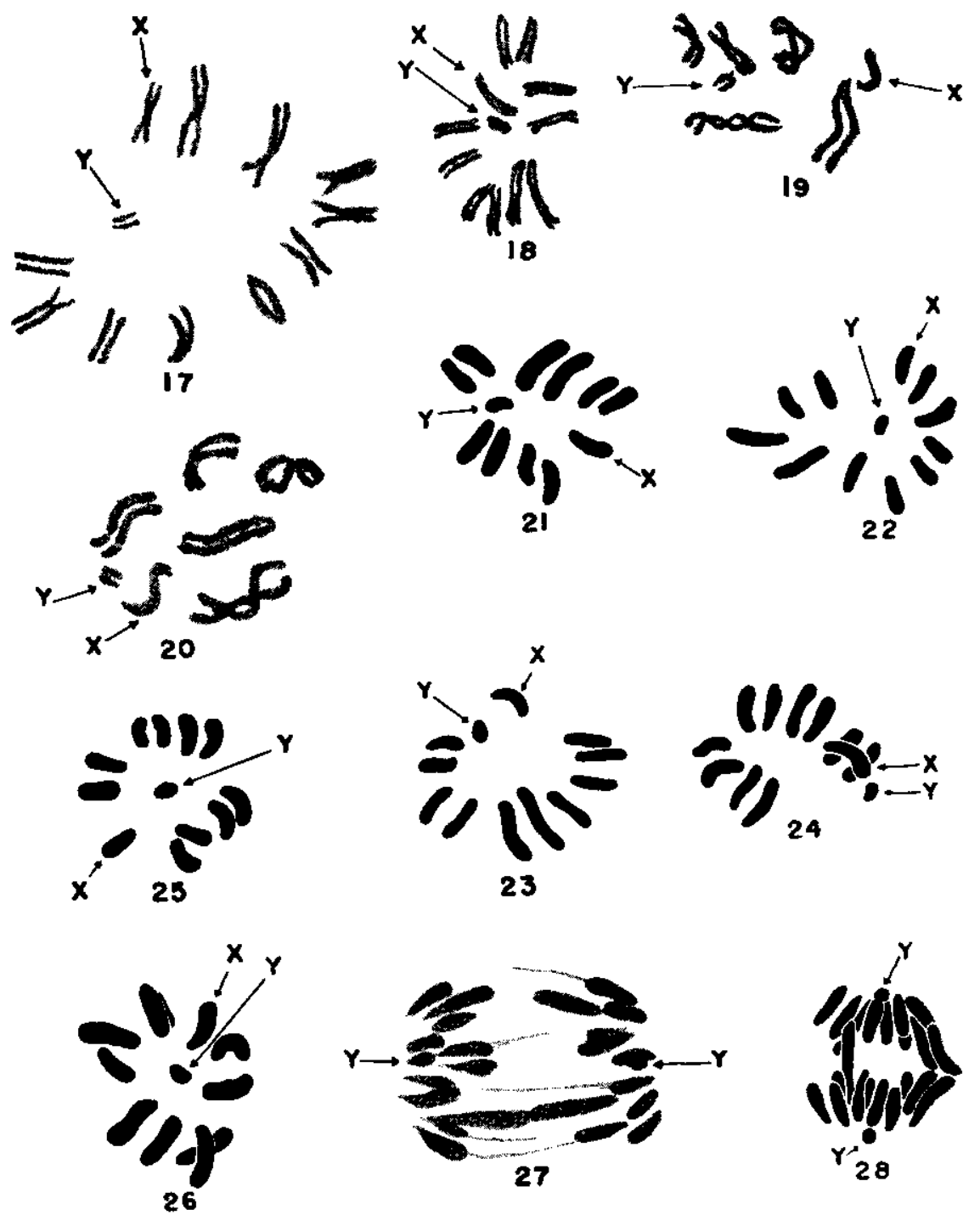

Figura 17-28. À Anastrepha fraterculus (Wied.): 17-18 - prófases; 19-20 prófases adiantadas; 21-26 - metáfases; 27-28 — anáfases. Tôdas em gânglios nervosos de larvas coletadas em laranja (Campinas, setembro de 1947). 
assinalado nas figuras (fig. 21 a 25). Em figuras anafásicas distingue-se perfeitamente o cromossomo $Y$ (fig. 27 e 28).

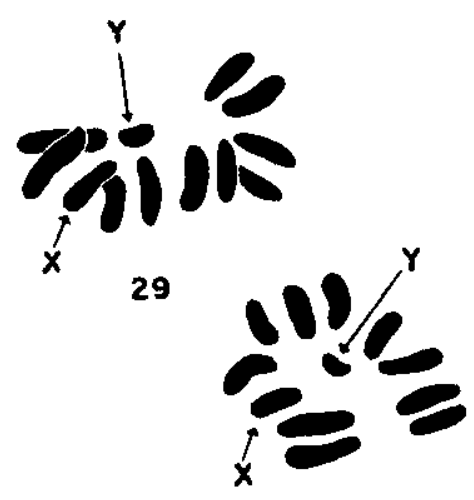

30

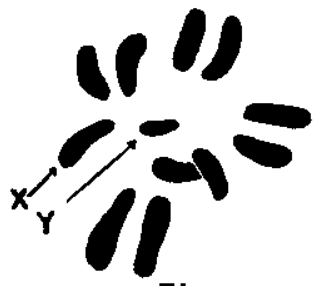

31

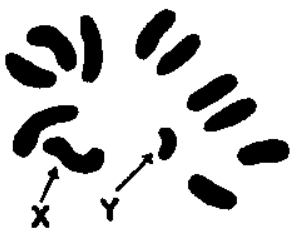

32

FigURA 29-32. Â Anastrepha fruterculus (Wied.): metáfases espermatogoniais em testículo de pupa obtida de nêspera (Limeira, outubro de 1947).

Em preparações obtidas de testículos de pupa observou-se que na primeira divisão meiótica vão para um polo $5 \mathrm{~A}+\mathrm{X}$ e para o outro, $5 A+Y$ (fig. 33); na segunda divisão os cromossomos dividem-se regularmente, dando células contendo respectivamente $5 A+X$ (como se conclui da observação da anáfase apresentada na figura 34), e $5 \mathrm{~A}+\mathrm{Y}$ (conclusão que se tira do estudo da figura 35 ).

Em testículo de adulto (obtido de nêspera, Limeira, outubro de 1947) foram observados os mesmos resultados atrás citados.

Nas preparações feitas não se observou a localização da constriçāo cêntrica, se bem que em um par de cromossomos somáticos haja uma diferençação cromática sub-terminal (fig. 20). No entanto, dada a forma que assumem os cromossomos em figuras anafásicas (fig. 16, 27 e 28) de tecido somático, bem como em figuras da primeira e segunda divisões meióticas (fig. 33, 34 e 35), pode-se concluir seja o centrômero de localização terminal ou sub-terminal.

Aliás o exame de figuras meióticas obtidas de testículo de adulto 
(obtido de nêspera, Limeira, outubro de 1947) corrobora tal ponto de vista (fig. 36 a 39).

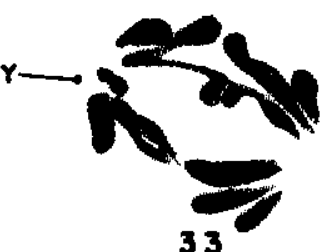

33

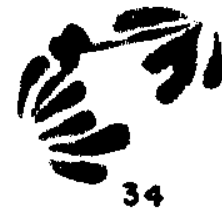

34

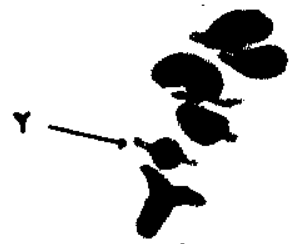

35
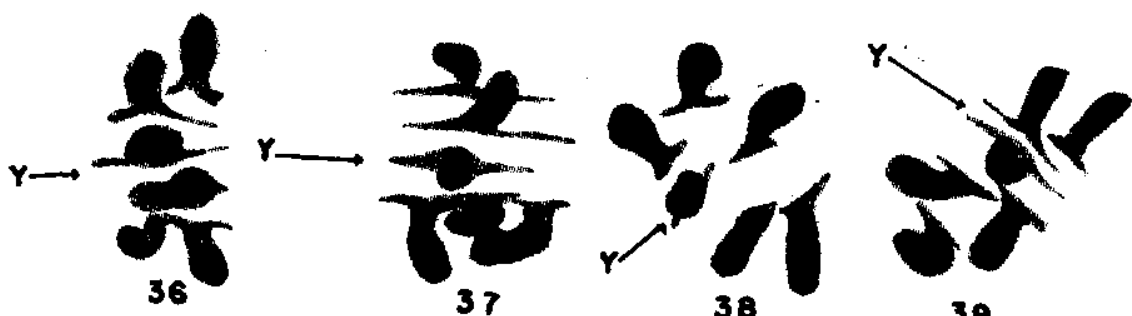

39

Figura 33-39. â Anastrepha fraterculus (Wied.): 33 - primeira divisáo meiótica;

34 - segunda divisão meiótica de espermatócito contendo $5 \mathrm{~A}+\mathrm{X}_{i} 35-39$ - segunda divisão meiótica de espermatócitos contendo 5A+Y. Tôdas em testículos de adultos obtidos de nêspera (Limeira, outubro de 1947).

Preparações de glândulas salivares revelaram a existência de cromossomos gigantes, que se desenovelam com relativa facilidade.

\section{CERATITIS CAPITATA. (WIED.)}

Estudou-se: a) tecido nervoso de larvas obtidas de pêssego (São Paulo, outubro de 1947); b) testículo de adulto obtido de pêssego (São Paulo, outubro de 1947); c) gânglios nervosos de larvas obtidas de laranja Pêra (Limeira, agôsto de 1948); d) ovório de fêmea adulta obtida de pêssego (São Paulo, outubro de 1947). Em todos os casos a coloração foi feita com orceina acética.

No tecido somático de larvas, machos e fêmeas, foram encontrados 12 cromossomos $(2 n=12)$.

Nas larvas fêmeas (obtidas de laranja Pêra, Limeira, agôsto de 1948) os cromossomos em prófase mostram-se constituidos de dois cro- 
matídeos dispostos paralelamente (fig. 40), sendo já visível o pareamento somático; em prófose mais adiantada (fig. 41 e 42) o pareamento é mais perfeito, exceto no que se refere a dois cromossomos que se apresentam mais afastados entre si. Em três pares de cromossomos (incluindo êste último referido) observa-se constrição cêntrica sub-terminal ( fig. 40, 41 e 42) enquanto nos outros três pares o centrômero parece ser de localização mediana, dividindo o cromossomo em dois braços de comprimento aproximadamente igual (fig. 42). Em pré-metáfase os cromossomos acham-se bem individualizados, sendo mantido o pareamento; a constrição sub-terminal em um par de cromossomos continua visível (fig. 43).
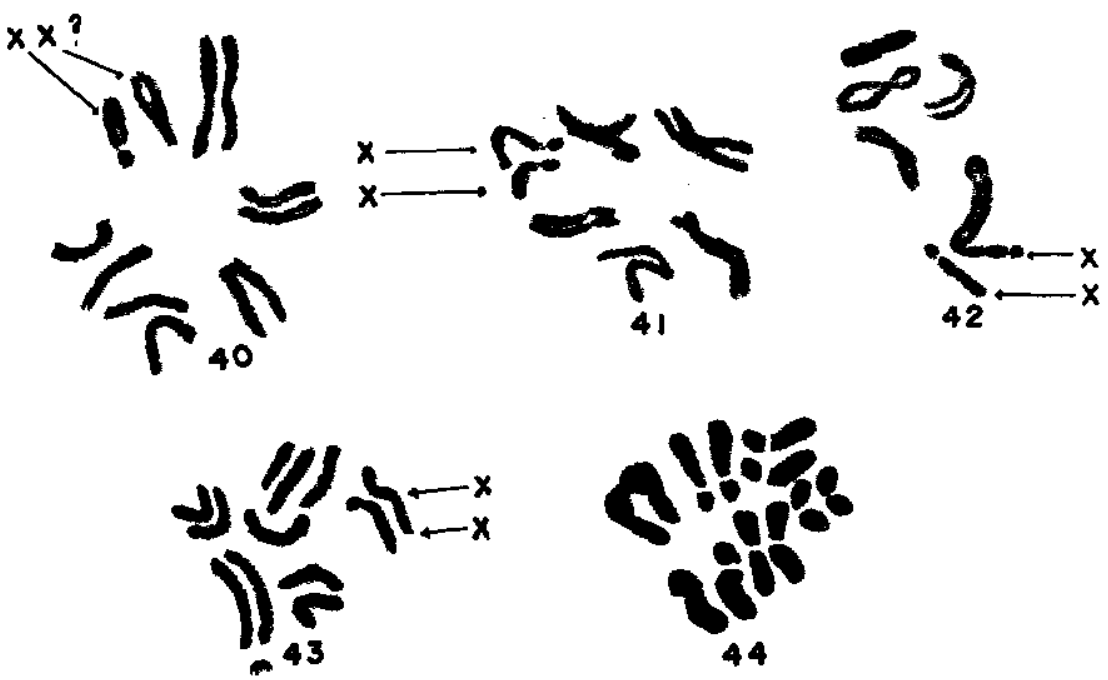

Frgura 40-44. क Ceratitis capitata (Wied.): 40-43 — prófases e pré-metáfase em gânglio nervoso de larva coletada em laranja Pêra (Limeira, agôsto de 1948); 44 - metáfase oogonial em ovário de adulto obtido de pêssego (São Paulo, outubro de 1947).

Em preparação de ovário de adulto (obtido de pêssego, São Paulo, outubro de 1947), foi observada placa metafásica constituida de 12 cromossomos dispostos oos pares, com constrição cêntrica bem visível, em três pares com localização sub-terminal, em dois pares localizada medianamente; no outro par não se observou claramente sua localização, parecendo estor aproximadamente no meio (fig. 44). 
Em larvas machas (obtidas de pêssegos, São Paulo, outubro de 1947) também foram encontrados 12 cromossomos. Em prófase, em 10 vê-se muito claramente dois cromatídeos em cada cromossomo e pareamento somático bastante distinto (fig. 45 a 47); os dois cromossomos não homólogos, um longo e provido de constrição cêntrica sub-terminal, e o outro menor e provido de satélite ou pseudo-satélite, não foram vistos pareados (fig. 45 a 48).

Em muitas prófase observa-se que os cromossomos homólogos se paream tão intimamente que se enrolam em espiral por quase todo seu comprimento, dondo a impressão de formarem quiasmas (fig. 49 a 51 ).
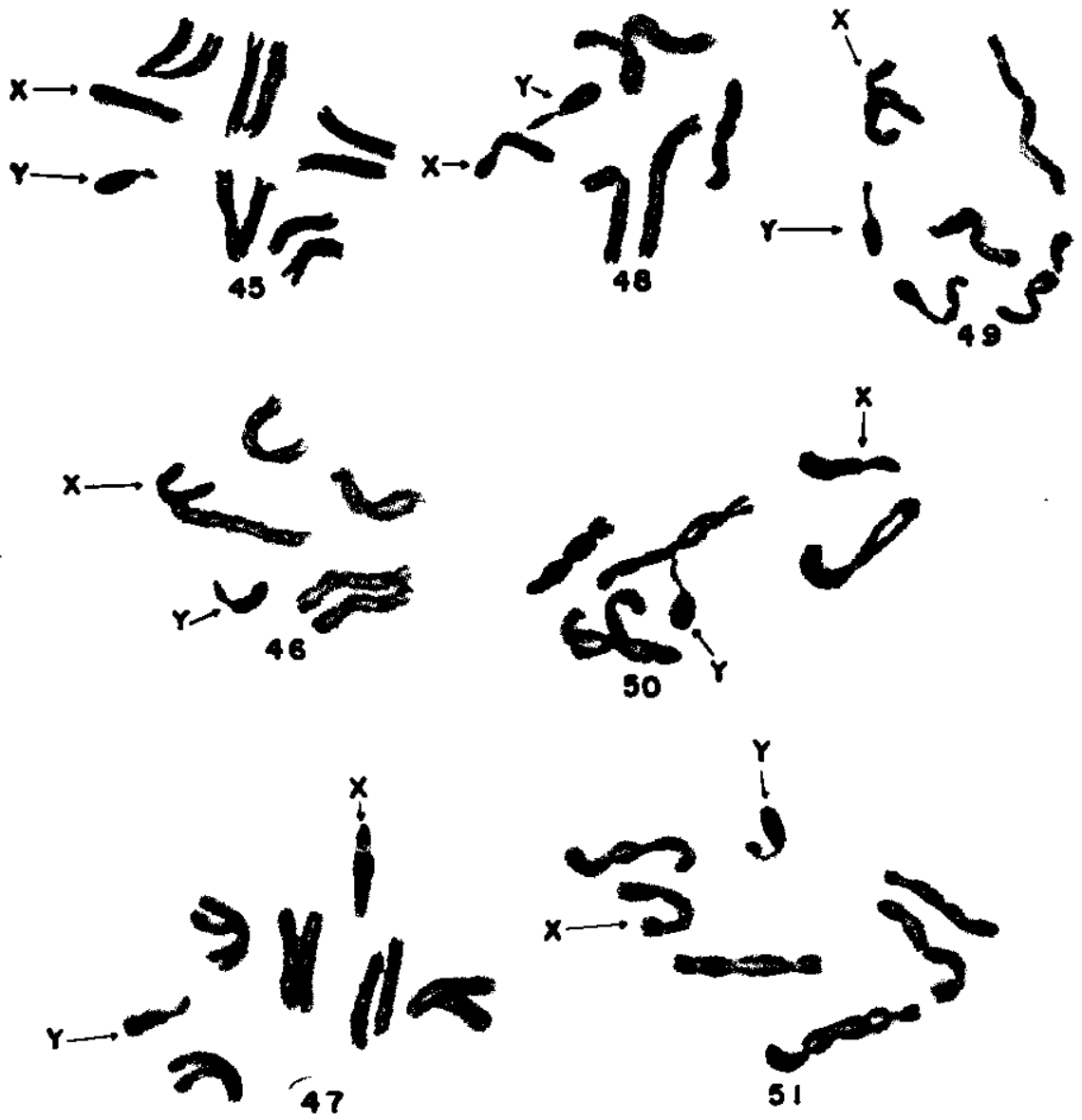

FIGURA 45-.51 ô Ceratitis capitata (Wied.): prófases em gônglios nervosos de larvas coletados em pêssego (São Paulo, outubro de 1947). 
Os dois hetero-cromossomos também nesses casos não mostram ter afinidade entre si, mantendo-se distanciados um do outro (fig. 49 a 51).

As configurações observadas em tecido somático de larvas, machos e fêmeas, bem como em tecido germinal de fêmea adulta, levam à conclusão de a fêmea ter seu complemento cromossômico constituido por $10 \mathrm{~A}+\mathrm{XX}$ e o macho, $10 \mathrm{~A}+\mathrm{XY}$. Dada a morfologia própria dos hetero-cromossomos existentes no macho, chamamos de $Y \circ$ cromossomo menor, provido de satélite ou pseudo-satélite, e de $X$ o mais longo, com centrômero de localização subterminal.

Em preparações feitas de testículos de adultos verificou-se ser $n=6$. Em figuras anafásicas pode-se observar que em alguns cromossomos o centrômero é de localização mediana e em outros, sub-terminal (fig. 52 e 53).
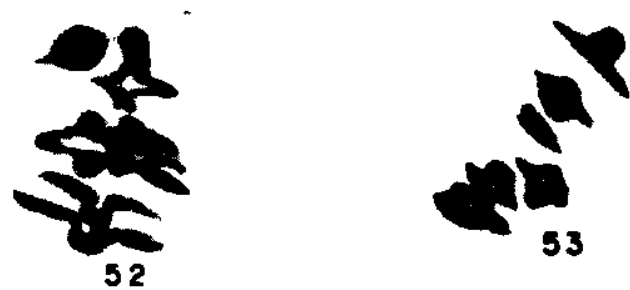

Figura 52-.53. o Ceratitis capitata (Wied.): anáfases meióticas em testiculo de adulto obtido de pêssego (Sõo Paulo, outubro de 1947).

Foi observada a existência de cromossomos gigantes em glândula salivar, tubos de Malpighi e intestinos de larvas desenvolvidas.

CONCLUSÕES. 1) Em células nervosas de larvas de Lonchaea penlula Bezzi foram encontrados três pares de cromossomos $(2 n=6)$, com centrômetro de localização mediana ou sub-mediana. Pode-se deduzir seja três, o número haplóide de cromossomos nessa espécie.

2) Em células nervosas de larvas, machos e fêmeas, de Anastrepha fraterculus (Wied.) encontram-se 12 cromossomos $(2 n=12)$. Nas fêmeas a fórmula cromossômica é $10 A+X X$ e nos machos, $10 \mathrm{~A}+\mathrm{XY}$. Ocorre pareamento somático bastante intenso entre os cromossomos homólogos.

3) Os espermatozóides de Anastrepha fraterculus (Wied.) são de duas classes, $5 A+X$ e $5 A+Y(n=6)$. 
4) Mesmo não se tendo visto a localização dos centrômeros em figuras mitóticas de Anastrepha fraterculus (Wied.), pelas configurações observadas em anáfase pode-se concluir sejam todos de localização terminal ou sub-terminal.

5) Em células de glândulas salivares de Anastrepha fraterculus (Wied.) foi observada a presença de cromossomos gigantes do tipo Drosophila.

6) Em células nervosas de larvas, machos e fêmeas, de Ceratitis capitata (Wied.) foram encontrados 12 cromossomos $(2 n=12)$. As fêmeas são de constituição $10 \mathrm{~A}+\mathrm{XX}$ e os machos $10 \mathrm{~A}+\mathrm{XY}$. Observa-se pareamento somático intenso entre os cromossomos homólogos.

7) Em Ceratitis capitata (Wied.), em três pares de autossomos o centrômero é de localização mediana, nos outros dois pares, de localizoção sub-terminal; no hetero-cromossomo $X$ o centrômetro é de localização sub-terminal. No cromossomo sexual $Y$ não foi precisamente determinada a localização do centrômero.

8) O cromossomo sexual $Y$ de Ceratitis capitata (Wied.) apresenta um pequeno corpúsculo distal, que pode ser classificado como: a) pseudo-satélite, se a constrição que o separa do cromossomo fôr realmente a constrição cêntrica; b) satélite, se não fôr essa a localização do centrômero.

9) Os óvulos de Ceratitis capitata (Wied.) sõo de fórmula cromossômica $5 \mathrm{~A}+\mathrm{X}$, e os espermatozóides, $5 \mathrm{~A}+\mathrm{X}$ ou $5 \mathrm{~A}+\mathrm{Y}$ $(n=6)$.

10) Em células de glândulas salivares, tubos de Malpighi e paredes intestinais de Ceratitis capitata (Wied.) foi observada a existência de cromossomos gigantes, do tipo clássico encontrado em Drosophillt.

11) Pela morfologia externa pode-se separar fàcilmente uma larva de Lanchaea pendula Bezzi de outras da família Trypetidae; como, porém, é muito difícil separar uma larva de Anastrepha fraterculus (Wied.) de outra de Ceratitis capitata (Wied.), o estudo de seu complemento cromossômico torna isso possível. 
12) Para o caso das três espécies citadas de "môscas das frutas", o estudo do complemento cromossômico de tecido somático permitiró a identificação específica das larvas da seguinte maneira:

a) Lonchaea pendula Bezzi, quando $2 n=6$;

b) Anastrepha fratercults (Wied.) quando $2 n=12$ e todos os cromossomos apresentarem centrômero de localização terminal ou sub-terminal; fêmea, quando forem encontrados seis pares de cromossomos somáticos; macho quando se encontrarem cinco pares de cromossomos somáticos, um hetero-cromossomo $(X)$ de forma e tamanho aproximadamente igual aos demais e um hetero-cromossomo $(Y)$ de tamanho menor que a metade de qualquer outro cromossomo;

c) Ceratitis capitata (Wied.) quando $2 n=12$ e se encontrarem cromossomos com centrômero de localização sub-terminal e outros de localização mediana; fêmea, quando forem encontrados seis pares de cromossomos somáticos; macho, quando além de cinco pares de cromossomos somáticos, fôr encontrado um hetero-cromossomo $(X)$ de tamanho aproximadamente igual ao dos autossomos, com centrômero de localização sub-terminal, e um outro hetero-cromossomo ( $Y$ ), um pouco menor que o $X$ e provido de satélite ou pseudo-satélite. SEÇÃO DE ENTOMOLOGIA, INSTITUTO AGRONOMICO DO ESTADO DE SÃO PAULO.

\section{CYTOLOGICAL OBSERVATIONS ON "FRUIT FLIES"}

\footnotetext{
SUMMARY

The author presents the results of some cytological studies on three species of "fruit flies".

Lonchaea pendula Bezzi (Lonchaeidae) has only three pairs of somatic chromosomes $(2 \mathrm{n}=6)$.

In Anastrepha fraterculus (Wied.) (Trypetidae) $2 n=12$. The females are $10 A+X X$ and the moles $10 A+X Y$. The $Y$ is the smallest chromosome of the set. In this species all centromeres seem to be terminal or subterminal. Giant chromosomes were observed in cells of the salivary glands.

In Ceratitis capitata (Wied.) (Trypetidae) $2 n=12$. The females are $10 \mathrm{~A}+\mathrm{XX}$ and the males 10A $+X Y$. In three pairs of autosomes the centromere is medion, and in two pairs subterminal. in the $X$ chromosome the centromere is subterminal. The $Y$ chromosome has a satellite or pseudosatellite. Giant chromosomes were observed in cells of the salivary glands, Malpighian tubes and intestins.

It is possible to identify the larvae of these three species of fruit flies by the morphology and behaviour of the chromosomes in somatic tissue.
} 